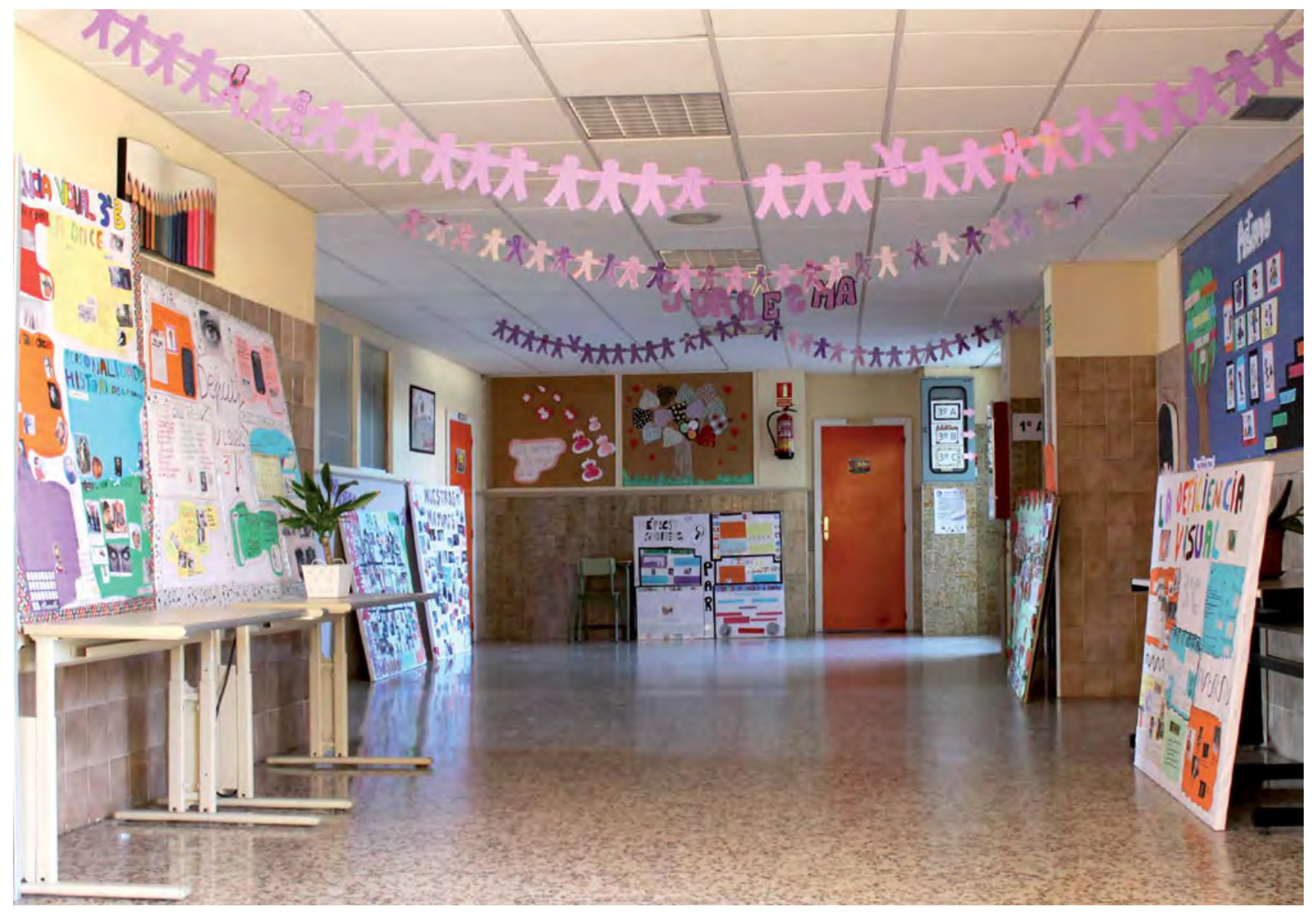

\title{
Un espejo en el que se reflejan tus alumnos cada mañana
}

Un camino que se empieza a recorrer siendo alumno y que continúa para formarse como profesor $y$ formar a futuras generaciones, para que sean seres responsables, autónomos y ciudadanos activos de nuestra sociedad, una formación integral es nuestro objetivo como

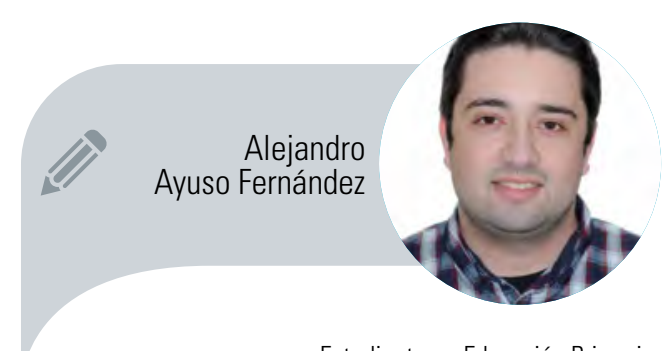

Estudiante en Educación Primaria, Universidad Pontificia Comillas. futuros maestros. Los cuatro años de prácticas aafernandez34@gmail.com te invitan a comenzar a subir ese peldaño que marca tu inicio de la carrera profesional docente. 
¿Ser maestro es tu vocación? ¿Ansías con ilusión enseñar y trabajar con los alumnos? ¿Cuáles han sido tus expectativas sobre la enseñanza y sobre ti como profesor a la hora de trabajar con los alumnos en un centro educativo?

Cuando te anuncian que vas a comenzar tus prácticas es un momento inolvidable. Por una parte, tienes un deseo enorme de que lleguen y poner en práctica todo aquello que sabes y ver si realmente eres un profesor. Sin embargo, un mundo es aquello que tú piensas que van a ser tus prácticas y otro la realidad a la que te enfrentas.

Los nervios, la ansiedad se pueden apoderar de ti en un primer momento y más si es tu primer día de prácticas. Nunca olvidaré la primera clase en la que aterricé, fue un $1 .{ }^{\circ}$ curso con alumnos de seis años. En un primer momento temía un $5 .^{\circ}$ o 6. ${ }^{\circ}$ de Primaria, que para mí era demasiado. Sin embargo, me sorprendieron las habilidades y la confianza con la que entré en el aula y comencé las clases. Aun así, me sucedió algo que jamás olvidaré y fue el hecho de tener que explicar la división a los alumnos de $3 .^{\circ}$ de Primaria de forma autónoma, ya que mi tutora aparte de trabajar en $1 .^{\circ}$, también daba Matemáticas en $3 .^{\circ}$ de Primaria. Ése quizás fue uno de mis principales desafíos nada más llegar. Al principio, observas como los nervios y las palpitaciones aumentan, puesto que es un gran desafío tener que enseñar por primera vez en tu vida un concepto tan abstracto como es éste y sin que tus alumnos lo hayan visto anteriormente. No obstante, para todo hay una primera vez y en aquella ocasión salí airoso y con la satisfacción de haber aprendido algo nuevo, tanto mis alumnos como yo mismo.

El control del aula ha sido uno de los ejes sobre los que he tenido que trabajar y sigo trabajando a lo largo de mis cuatro años de prácticas. Dependiendo del curso, el nivel de dificultad aumentará o disminuirá. Al principio, como los tres primeros años de prácticas han sido en cursos bajos como $1 .^{\circ}$ o $2 .^{\circ}$ de Primaria, el control del aula es bastante grande, porque los alumnos son más obedien-

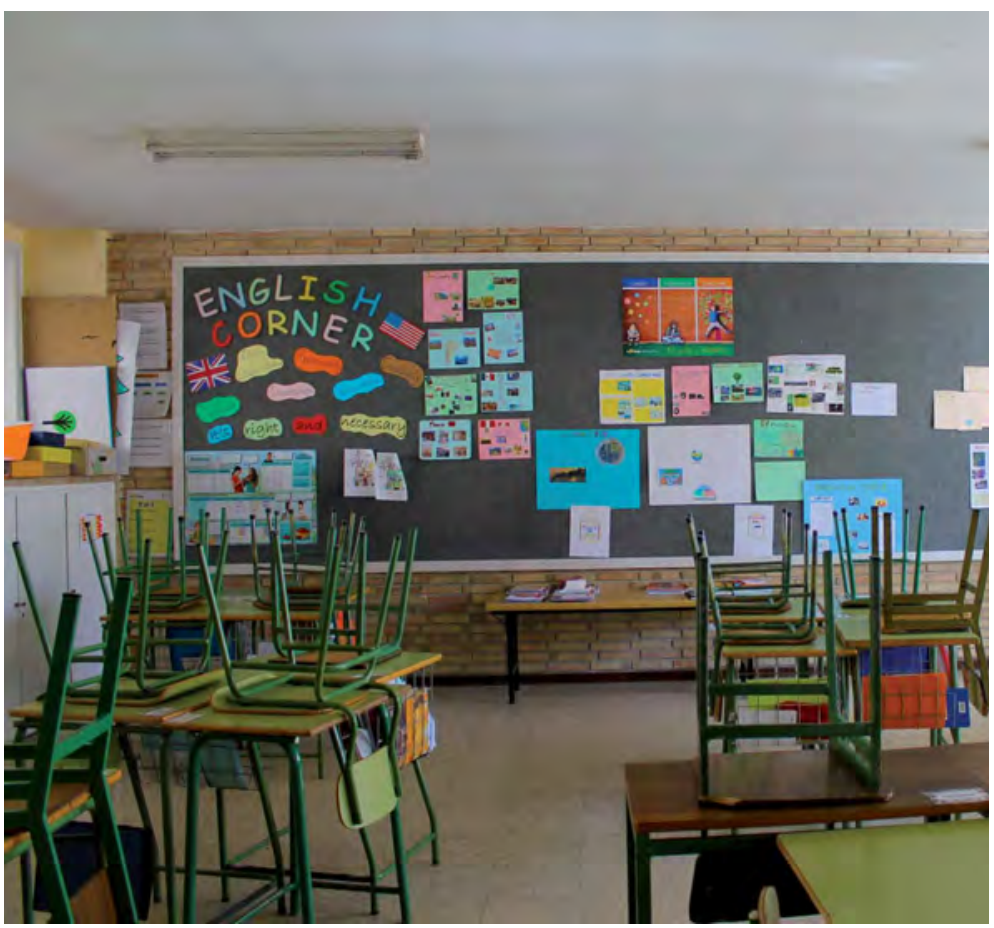

tes, no tienen ese comportamiento que pueden llegar a tener algunos alumnos de cursos superiores, desafiante o transgresor de las normas, características que se pueden encontrar en los otros cursos restantes. Sin embargo, dominar $4 .^{\circ}, 5 .^{\circ}$ y 6. ${ }^{\circ}$ de Primaria ya implica un grado mayor de complejidad. Conversando con una de mis profesoras de este año en $4 .^{\circ}$ de Primaria me comentó que ése es uno de los desafíos a los que todos los profesores en prácticas nos enfrentamos. La experiencia en el aula y los años te ofrecerán la oportunidad de adquirir técnicas de control del grupo, pero, aun así, hay que saber que no se puede tener el 100\% del control sobre un grupo, siempre se tiene que dejar cierta fluidez y que los alumnos conversen, y más teniendo en cuenta que hoy en día se trabaja a través de la metodología de aprendizaje cooperativo. Pero todo ello requiere práctica y experiencia, que no deja de ser la base del aprendizaje.

La preparación de las clases no es un aspecto que surja de la pura improvisación, siempre, a la hora de preparar una clase, tengo que tener en cuenta una serie de elementos que son imprescindibles para que lo que has preparado tenga un resultado óptimo. Por eso, siempre es conveniente que, tanto si sale bien o mal, apuntes y reflexiones cómo crecer a nivel profesional, qué fortalezas y debilidades has observado y cómo se podrían mejorar. 


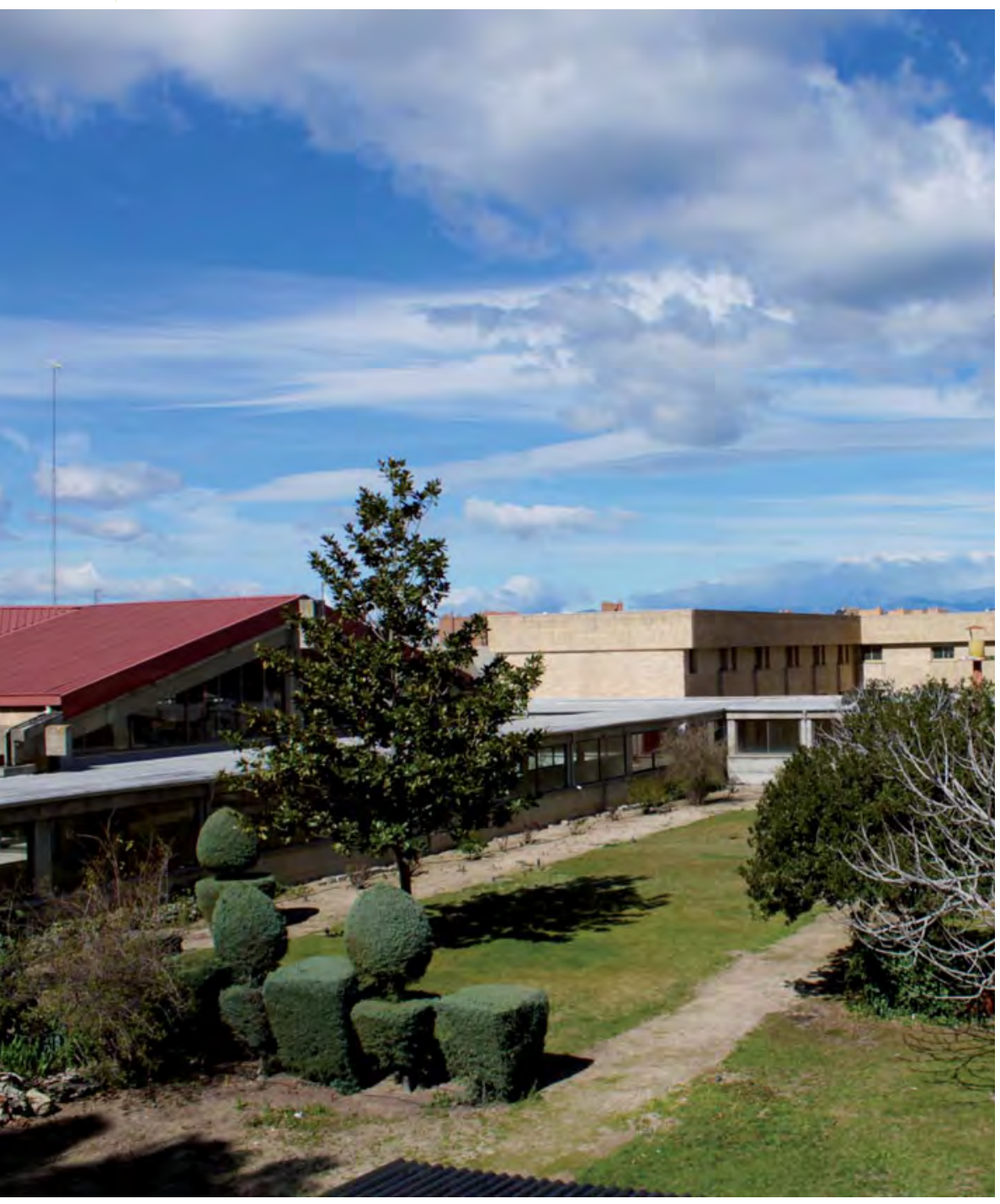

La formación inicial que recibes a lo largo de toda la carrera de magisterio te va dotando de pequeños ingredientes que forman parte de tu yo docente. Cada año vas aprendiendo algo nuevo; lo que el primer año resulta complejo, imposible de alcanzar, te vas dando cuenta, de que no lo es o no en gran medida, cuando pasas el ecuador del grado.

Al mismo tiempo, la perspectiva que tienes antes de empezar la carrera, durante la misma y una vez graduado se modifica por completo en la mayoría de los casos. Porque tanto la formación teórico-práctica recibida en la universidad como aquella vivida en las prácticas te sirven como platos principales de un menú que es tu aula, del cual tú sirves como camarero, alias docente, y del que al mismo tiempo te sirves tú como cliente. Con lo cual, es un elemento recíproco a todos los efectos.
La observación será una de las acciones más habituales que se realicen en cualquier tipo de periodo de prácticas. Al principio, puede llegar a ser un tanto tedioso, pero realmente a través de la misma puedes lograr entender un gran elenco de elementos. El comportamiento, las relaciones sociales, la forma de interacción en el grupo-aula son aspectos que debes observar, que te ayudarán a la hora de intervenir con los alumnos; ver cómo tu tutor imparte las clases y los enseña, cómo se dirige a ellos, qué instrumentos o técnicas utiliza para el control y gestión del aula, en qué materiales se apoya o utiliza. Todo ese conjunto de ideas y elementos que se citan son un aprendizaje rico y muy nutritivo para cualquier maestro que se esté formando ya sea en la universidad como a lo largo de su carrera profesional como docente.

La reflexión sobre aquello que te ha ocurrido, cómo lo has trabajado, qué aspectos mejorarías, qué metas te propondrías, es fundamental en el recorrido de cualquier docente. En la universidad se realiza a través de foros de intercambio de experiencias, entrevistas con los supervisores, pero en realidad aparte de estos espacios, tú mismo como maestro debes reflexionar en tu aula sobre aquello que te habías propuesto, cómo lo has realizado, si se ha conseguido y cómo mejorarlo. La mejor manera de poder autoevaluarte e ir modificando y haciendo más ricas tus clases es a través de ese proceso reflexivo.

La iniciativa y participación son ingredientes que hay que tener a la hora de practicar. La única manera de aprender a ser profesor es haciendo, practicando, arriesgándose a realizar ejercicios, tareas y actividades con los alumnos, porque todo eso te abrirá numerosas fuentes de aprendizaje y te enriquecerá como profesor. Especialmente te ayudará a saber y descubrir tus habilidades, aquello que debes reforzar, pero sólo si te muestras predispuesto a colaborar, a traer ideas nuevas al aula, a realizar proyectos. Esto requiere de trabajo y preparación, pero es muy beneficioso para tu propio crecimiento personal y docente, ir haciendo 

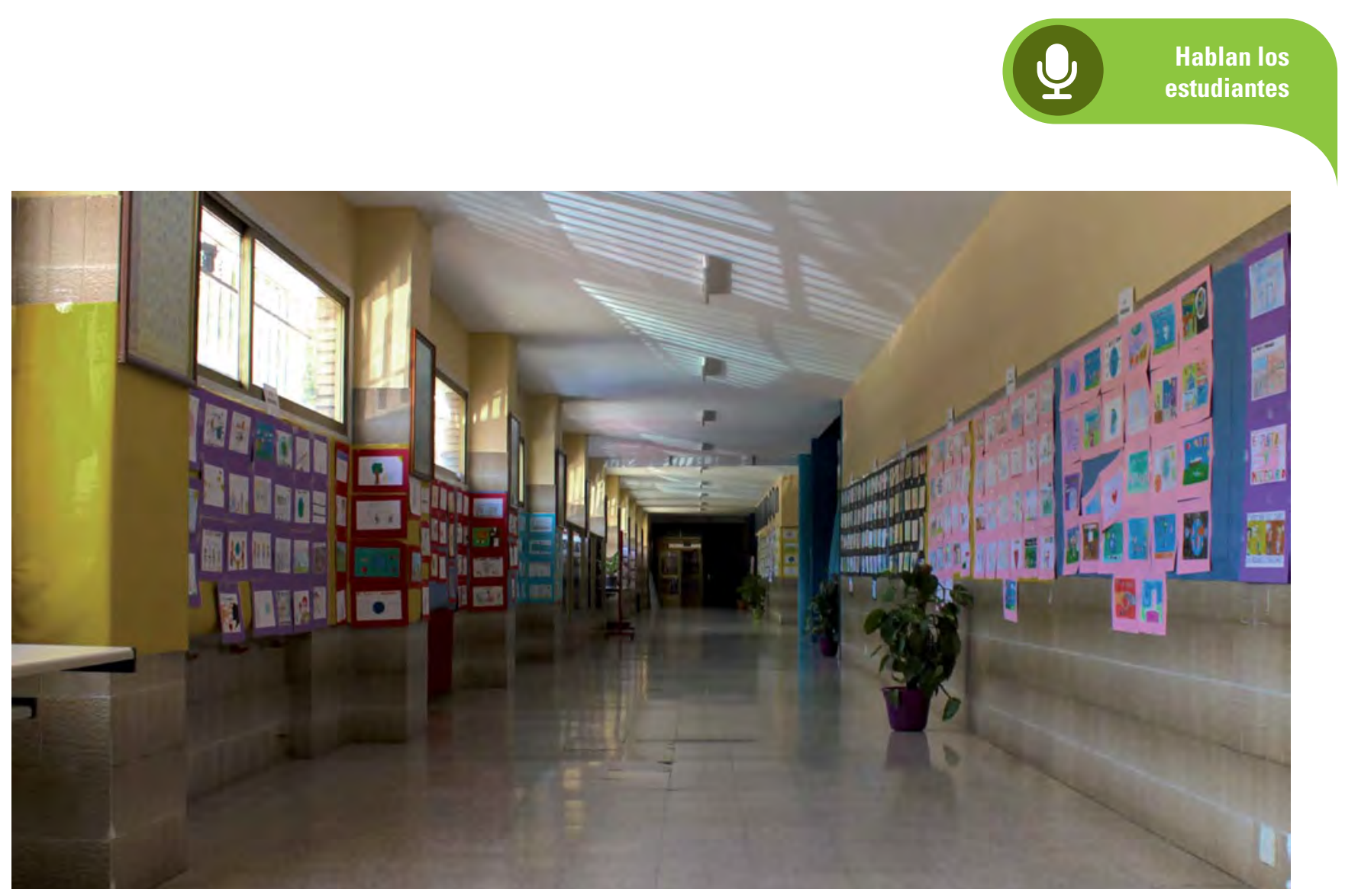

poco a poco trabajos con los alumnos y siendo capaz de aunar lo que aprendes en la universidad con aquello que realizas y aprendes en las prácticas.

La pragmática es una de las competencias que todo maestro que esté formándose debe conocer y aplicar en el aula. El lenguaje con el que nos dirigimos a nuestros alumnos debe ser el adecuado al contexto o a la situación en la que nos encontremos. Aún más, en función de la edad que tengan los alumnos, también habrá que adecuar la entonación, la velocidad y el ritmo en la explicación.

Los ritmos, las rutinas y los espacios son aspectos que se observan en el aula. Es muy enriquecedor poder cambiar de curso a lo largo de todas tus prácticas para que así tengas una visión de cómo se trabaja en cada uno de ellos. En mi primer año de prácticas, mi tutora me dijo que $1 .^{\circ}$ de Primaria requería de paciencia y un ritmo lento, elemento que en muchas ocasiones al ser novatos en este tipo de profesión, no solemos tener en cuenta, pero que es crucial en el desarrollo de cualquier tipo de actividad que realicemos con los alumnos.

Por otra parte, destacar la ilusión y la alegría con la que te reciben tus alumnos o cómo colaboran y te ven como una figura referente. La satisfacción de ver cómo aprenden todo aquello que tú les enseñas, no sólo con aquello que les muestras como contenido, sino con tus acciones, con la forma en la que explicas, en todo se fijan tus alumnos, porque eres el espejo en el que se reflejan, aparte de sus padres, en ti ven todo lo que tienen que aprender. Por ello, cuando estás en el aula, tu postura, tu expresión y todo aqueIlo que acontece alrededor es importante para tu enseñanza y para el aprendizaje de tus alumnos.

En definitiva, como en toda profesión, encontrarás ventajas e inconvenientes, pero ver la cara de satisfacción de aprendizaje de un alumno, anula cualquier inconveniente que puedas encontrar. Es un camino con obstáculos pero en el que finalmente la recompensa es la mayor que un maestro se puede encontrar a lo largo de su carrera y es ver que tus alumnos aprenden y que son lo que son, gracias a tu formación durante su infancia •

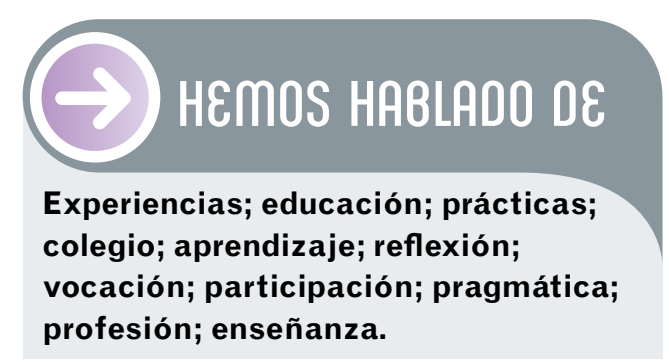

Este artículo fue solicitado por PADRES y MAESTROS en diciembre de 2015, revisado y aceptado en julio de 2016.
Todas las fotografías utilizadas en este artículo pertenecen al centro educativo La Salle Sagrado Corazón de Jesús de Madrid 